\title{
Ontogênese do estético e vissungos: cantos de trabalho dos negros escravizados na mineração
}

\author{
Marlon Garcia Silva ${ }^{1}$ \\ https://orcid.org/0000-0003-1574-7732 \\ ${ }^{1}$ Universidade Federal de Ouro Preto, Departamento de Serviço Social, Curso de Serviço Social, Mariana, MG, Brasil
}

\section{Ontogênese do estético e vissungos: cantos de trabalho dos escravizados na mineração}

Resumo: O artigo, num primeiro movimento, recupera categorias da estética marxista e trata em termos gerais da ontogênese do ritmo, do canto, das categorias da autoconsciência e da antropomorfização de caráter estético, dimensionando a capacidade humana de dominar por essas vias o entorno e as forças socialmente desencadeadas; num segundo movimento, são tratados os vissungos, cantos de trabalho, resistência e luta dos negros escravizados nas atividades da mineração, numa discussão de suas bases de entificação e função social, quando as categorias estéticas inicialmente tratadas em termos ontogenéticos reaparecem e são tratadas de forma concreta, no âmbito de uma formação social específica.

Palavras-chave: Estética. Marxismo. Cantos de trabalho. Vissungos.

\section{Ontogenesis of the aesthetic and vissungos: work songs of the slaved in mining}

Abstract: This article, in a first movement, recovers categories of Marxist aesthetics and deals in general terms with the ontogenesis of rhythm, singing, dimensioning human capacity to dominate the surroundings and socially unleashed forces; in a second movement, search the vissungos, working songs, resistance and struggle of blacks enslaved in mining activities are treated, in a discussion of their bases of understanding and social function, when aesthetic categories initially treated in ontogenetic terms reappear and are concretely treated, as part of a specific social formation.

Keywords: Aesthetics. Marxism. Work songs. Vissungos.

Recebido em 31.10.2019. Aprovado em 11.02.2020. Revisado em 08.04.2020.

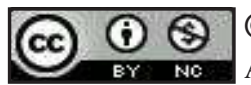

(C) O(s) Autor(es). 2020 Acesso Aberto Esta obra está licenciada sob os termos da Licença Creative Commons Atribuição-NãoComercial 4.0 Internacional (https://creativecommons.org/licenses/by-nc/4.0/deed.pt_BR), que permite copiar, distribuir e reproduzir em qualquer meio, bem como adaptar, transformar e criar a partir deste material, desde que para fins não comerciais e que você forneça o devido crédito aos autores e a fonte, insira um link para a Licença Creative Commons e indique se mudanças foram feitas. 


\section{Introdução}

György Lukács, na sua obra A peculiaridade do estético, de 1963, confrontando as tradições do idealismo filosófico, explicita o intento de tratar as categorias estéticas sobre bases histórico-materialistas, partindo dos fundamentos da produção e da reprodução da vida social. De modo que as categorias objetivas e subjetivas do ser social, no interior das quais encontram-se as capacidades de produção e fruição estéticas de homens e mulheres, não são tomadas como atributos intrínsecos, absolutos, dispostos aprioristicamente no "espírito" humano, antes, são predicados forjados nos processos de humanização, na história. Acompanhando as teses de Marx, o autor investiga a partir da "forma da atividade" (MARX, 2010, p. 84) - que traz consigo a socialidade - o caráter específico do humano. É a potência de produzir um mundo próprio de objetos e relações que institui e eleva da natureza o humano, confirmando na prática o saber e a subjetividade como potências efetivas, específicas, desta forma de ser.

Pode-se afirmar que tais enunciados de caráter geral, antes de qualquer arbitrariedade, são parametrados e sustentados pelas evidências prático-sensíveis das formas sociais mais complexas e cotidianas, tais como aquelas empiricamente constatáveis nos marcos da sociedade burguesa. A análise desta formação social põe em evidência que tal como os homens "exteriorizam" e produzem a "sua vida assim são eles", "o que eles são coincide com a sua produção, tanto com o que produzem como também com o modo como produzem" (MARX; ENGELS, 2007, p. 87). Tais referências balizadoras, razoáveis, mais gerais, não apenas abrem para incursões pela história humano-genérica em seus processos particulares, como possibilitam o enfrentamento de um problema de grande dificuldade, qual seja, o da gênese do humano e das suas categorias específicas. A esse respeito, Lukács ressalta a óbvia impossibilidade da recuperação de material fáctico, de caráter empírico, comprobatório do salto ontológico que o humano realiza em relação ao meramente natural. Nesse sentido, "todos os fatos que podem oferecer-nos a etnografia, a arqueologia, etc. se referem a situações incomparavelmente mais evoluídas" (LUKÁCS, 1966, p. 82). O que não significa fechamento para essa compreensão ontogenética. O autor defende, a partir dos parâmetros e balizamentos gerais mencionados nas presentes linhas, a possibilidade e a potência da elaboração de "hipóteses reconstrutivas dos fatos" (LUKÁCS, 1966, p. 82), matrizadas na forma específica da atividade, de produção e reprodução da vida social. Essas referências gerais que abrem para incursões sobre formações sociais diversas no tempo e no espaço não fornecem, contudo, qualquer elemento de caráter histórico-concreto, o que só pode ser obtido mediante o trabalho e os resultados de investigações mais especializadas. Daí o desafio e a vantagem de se encontrar situações sociais com "um mínimo de objetivações" (LUKÁCS, 1966, p. 83), e também a importância de se escavar elementos de formações sociais específicas mediante trabalhos científicos arqueológicos, etnográficos, etc., elementos oriundos do acervo do humano em sua pluralidade e generidade.

A partir desses pressupostos, orientações e teses, o presente artigo, num de seus movimentos, trata em termos gerais e aproximativos da gênese estética do ritmo e do canto a partir da forma específica da atividade humana, do trabalho, fazendo indicações das relações desses processos ontogenéticos com o despontamento das categorias da autoconsciência e da antropomorfização de caráter estético, categorias mediante as quais os homens, por vias específicas, expandem seus domínios subjetivos e práticos sobre o mundo natural e principalmente sobre o mundo socialmente constituído. Num outro movimento principal, sensível à riqueza do acervo humano-genérico em sua pluralidade e diversidade - não obstante as relações contraditórias, de dominação e violência, próprias das sociedades de classe -, a análise volta-se aos vissungos, cantos de trabalho, resistência e luta dos negros escravizados nos grilhões da mineração, nas relações de expropriação da riqueza e da vida desde o "Brasil colônia". A fonte principal desta análise é o livro O Negro e o garimpo em Minas Gerais, de Aires da Mata Machado Filho, publicado em 1938, no qual encontram-se reunidos 65 vissungos coletados pelo pesquisador em seus trabalhos etnográficos.

Assim, à investigação mais geral das categorias estéticas a partir dos processos de humanização se soma e se articula, no que segue, a escavação de categorias e expressões estéticas mais particulares radicadas numa formação social e num grau de objetivação social específicos, o que potencializa o esclarecimento dos nossos processos humano-genéricos, na particularidade de povo latino-americano, brasileiro.

E sabido que as teses marxistas sobre a vida social têm sido, para dizer o mínimo, lateralizadas na cultura acadêmica, universitária, burguesa, contemporânea. Também pode-se afirmar que as teses lukacsianas estão longe de uma repercussão expressiva no âmbito do marxismo, principalmente quando a referência são as obras de maturidade do autor, como A peculiaridade do estético e Para uma ontologia do ser social, obras geralmente desconhecidas ou desconsideradas. Na contramão dessas tendências, defende-se no presente artigo que os escritos de maturidade deste autor podem contribuir para uma revitalização do marxismo e da cultura crítica - teórica e prática - contemporânea. 


\section{Forma da atividade e ontogênese do ritmo}

Nas elaborações da Estética, tratando dos problemas ontogenéticos das categorias sociais, com o interesse de apreender e destacar aquelas que vão constituindo a peculiaridade do estético, Lukács faz uma série de comparações das formas de ser e das determinações da existência próprias do ser social com aquelas que são próprias do ser natural. Ao tratar das chamadas formas abstratas do reflexo da realidade, que vão sendo forjadas nos processos de humanização, entre elas, o ritmo, a simetria e a proporção, o autor identifica a presença de tais formas já na natureza. É assim que o ritmo é reconhecido teoricamente como fenômeno natural e biológico, quando são considerados, por exemplo, fenômenos cíclicos naturais, regulares, como o dia e a noite, as estações do ano, etc., e também quando se toma a própria existência biológica dos animais, que compreende fenômenos rítmicos tais como a respiração e a pulsação. Já nesses fenômenos, o ritmo identificase ao funcionamento regular de processos naturais vitais, vale dizer, constitui-se como dinâmica e força ligadas ao favorecimento e à facilitação da vida. Pode-se afirmar que essa dinâmica favorável à vida exerce uma influência edificadora sobre os sentidos, as percepções, as representações e os comportamentos que se formam já no mundo animal. Assim, no exercício e nas experiências que vão sendo obtidas e acumuladas na construção e defesa da existência, se produzem "hábitos motores que no curso de um tempo dilatado fazem desses fundamentos reflexos incondicionados pelos quais se realiza quase automaticamente o modo mais cômodo ou menos fatigoso de realização" (LUKÁCS, 1966, p. 268), como ocorre no caso do "voo dos pássaros e na marcha dos animais e do homem" (LUKÁCS, 1966, p. 268).

Contudo, diferentemente dos animais, os homens, na construção da sua existência, não marcham nem atuam orientados por instintos naturais, mas por finalidades previamente ideadas, subjetivamente (e socialmente) estabelecidas. O sujeito e a subjetividade nascem desde que "no trabalho o homem toma um pedaço da natureza, o objeto de trabalho, e o arranca de sua conexão natural, o submete a um tratamento pelo qual as leis naturais são aproveitadas teleologicamente em uma posição de fins" (LUKÁCS, 1966, p. 268). Ao "tomar um pedaço da natureza", "arrancá-lo de sua conexão natural”, produzir algo útil à satisfação de determinada necessidade, ao "aproveitar teleologicamente" as causalidades e legalidades da natureza, o homem instaura processos, movimentos e regularidades próprios, distintos daqueles naturais.

Com o trabalho, surgem e se desenvolvem processos e "hábitos motores" radicados na capacidade teleológica do ser humano. O sentido humano do ritmo nasce com a capacidade da regularização consciente de movimentos no trabalho. O homem descobre que a reiteração regular de movimentos espaço-temporais agiliza, facilita e favorece a execução da atividade, o alcance dos fins ideados, a obtenção dos resultados pretendidos. A ritmização da atividade permite a otimização do emprego de energia, reduzindo desgastes, e favorece, por meio da repetição, a exercitação de movimentos, músculos etc. Ela imprime aos movimentos do trabalho uma relativa automatização, o que permite que o emprego da vontade se torne intencionalmente uma força secundária, até que intervenha "um novo exercício da vontade" (LUKÁCS, 1966, p. 269) (aceleração ou desaceleração da atividade, interrupção etc.). A esse respeito, Lukács (1966, p. 269) afirma que "a tensão intelectual durante o trabalho pode diminuir-se mediante a automatização, a conversão dos movimentos em mecânico-voluntários. Esta é precisamente a função do ritmo".

O ritmo, por seu caráter, sua utilidade e eficácia, na medida em que potencializa objetivamente o trabalho, facilitando e favorecendo a execução da atividade e a obtenção dos resultados visados, liga-se ao desencadeamento no homem de sensações de alívio e prazer e, nesse sentido, à produção de sentimentos e emoções agradáveis, numa dinâmica de expansão das suas capacidades subjetivas. Para além do âmbito do trabalho em sentido estrito, o ritmo vai sendo crescentemente tomado e reconhecido também afetivamente como elemento do mundo próprio do homem. Por essas vias dá-se a possibilidade da separação e independização do ritmo de suas funções concretas no trabalho, o trânsito de sua constituição como momento da vida e da atividade humana a reflexo dessa realidade, a momento subjetivo, o que corresponde, conforme as teses de Lukács, às formas germinais da categoria da autoconsciência.

\section{Forma da atividade, ritmo e ontogênese dos cantos de trabalho}

Ao tratar dos problemas da ontogênese do ritmo, do caráter e da função específicos que o mesmo assume objetiva e subjetivamente na vida social, Lukács fornece também algumas indicações pontuais, contudo, bastante instrutivas, sobre a ontogênese dos cantos de trabalho.

Uma forma primária de imbricação entre ritmo e som pode ser identificada no fato de que no trabalho "o contato da ferramenta com o objeto de trabalho é sonoro" (LUKÁCS, 1966, p. 270), de modo que os movimentos regulares, por exemplo, de golpe e recuo do instrumento sobre o objeto produzem sonoridades já relativa- 
mente complexas em sua composição física, intensidades, tons, timbres, andamentos etc. Essa sonoridade percussiva vai constituindo uma forma específica de expressão material-sensível das capacidades humanas de trabalho, de ritmização da atividade, de domínio das forças da natureza, uma forma que os homens passam a sentir, a reconhecer e a dominar subjetivamente como própria.

Nesses processos e dinâmica de expansão das capacidades subjetivas, de humanização dos sentidos, os cantos de trabalho surgem com a vocalização de "sons não articulados", "semianimais" (LUKÁCS, 1966, p. 276-277), que acompanham a atividade e os ritmos do trabalho, integrando e potencializando o complexo subjetivo-emocional que expressa e robustece os sentimentos humanos, por exemplo, as referidas sensações de alívio e o sentimento de satisfação dos homens no desempenho e realização das suas atividades. Essa elaboração humana, social, dos sons físicos-naturais, das capacidades vocais, percussivas etc., vai constituindo, pois, uma forma peculiar de expressão e comunicação sensível, não verbal, na qual “o que importa é o efeito musical, o ritmo sonoro como apoio e sustentação do ritmo de movimento" (LUKÁCS, 1966, p. 277).

Vale considerar aqui que os mesmos princípios e fundamentos que possibilitam essas indicações aproximativas da ontogênese do ritmo e dos cantos de trabalho abrem para a compreensão de certas linhas tendenciais do desenvolvimento histórico-social. Os processos de humanização são, em sentido amplo, processos de "recuo das barreiras naturais" e de avanço das categorias sociais. Em consonância com essa dinâmica, é razoável considerar que em formações sociais mais recuadas, os ritmos e os cantos de trabalho, mais colados às formas concretas da atividade, tendem a expressar, por exemplo, um "conteúdo" emocional "menos diferenciado" (LUKÁCS, 1966, p. 277), uma menor variação percussiva, dos sons vocais de acompanhamento, etc. Interessa aqui apontar essa tendência na medida em que, por um lado, conforme sinalizado, é impossível alcançar com base em documentos empíricos esses processos ontogenéticos em suas manifestações histórico-concretas, sensíveis. Por outro lado, essa linha tendencial do desenvolvimento social abre para a consideração de formações sociais mais complexas, mais densas. Nesse sentido, vale destacar que Lukács considera que "a grande maioria" dos "cantos de trabalho" de que se tem registro "procede de um período no qual o comunismo primitivo já se dissolveu", quando "o trabalhador que canta é já um explorado, muito frequentemente um escravo", sendo que "o conteúdo emocional desses cantos tem, consequentemente, uma complicação (trabalho como coação, como exploração, temor ao senhor ou ao vigilante, lamento, rebelião etc.) que não podem ter possuído os simples cantos de trabalho de uma sociedade sem classes" (LUKÁCS, 1966, p. 277).

A consideração de formações sociais mais complexas e contraditórias, que corresponde ao avanço da escavação e da análise de um conjunto mais amplo de determinações sociais, favorece a dissolução das abstrações iniciais bastante amplas, no sentido de uma consideração mais concreta das categoriais sociais, no caso, mais especificamente, das categorias estéticas. $\mathrm{O}$ esboço deste quadro de referência é importante para a consideração, mais à frente, dos vissungos.

\section{Autoconsciência e ontogênese do estético}

A análise do trabalho, da forma específica da atividade humana, que remete aos seus desdobramentos na constituição de um mundo próprio, social, de objetos e relações, e à expansão desse mundo, das categorias sociais objetivas e subjetivas, atesta que o homem, nos seus processos autoconstitutivos, busca e precisa submeter a si não apenas as forças da natureza, mas também as forças e relações que são socialmente desencadeadas, postas. A autoconsciência corresponde à forma específica de reflexo pela qual a subjetividade toma por objeto e matéria o próprio mundo humano, social, que vai se constituindo, desprendendo e adensando a partir do metabolismo primário homem-natureza.

Em conformidade com a argumentação em curso, cujo interesse se concentra, sobretudo, na ontogênese desses processos, convém ressaltar o movimento pelo qual o sentido humano do ritmo, nascendo do trabalho, ou seja, constituindo-se inicialmente como "momento reativo real" - facilitador e promotor - do "processo de trabalho" (LUKÁCS, 1966, p. 292), passa a ser, ele próprio, tomado, refletido e reconhecido subjetivamente, racional e afetivamente, como elemento próprio do mundo humano. Esse processo põe em evidência as conexões, as transições e as especificidades entre o complexo do útil, na relação consciente do homem com o mundo externo, e o complexo do agradável (LUKÁCS, 1967, p. 217), que corresponde aos desdobramentos internos, autorreflexivos, dos processos de autossatisfação dos homens, nos domínios do entorno e de si.

Esses movimentos de expansão da subjetividade atestam as possibilidades de separação e independização do ritmo de suas funções concretas no âmbito do processo de trabalho, sua conformação subjetiva como patrimônio dos homens, patrimônio que pode ser disposto e estendido para outros campos da atuação humana, inclusive aqueles que vão constituindo domínios mais espiritualizados. Para essa dinâmica expansiva concorre, conforme a presente argumentação, o desenvolvimento das forças e capacidades produtivas sociais, na produ- 
ção humana de um mundo próprio. Nesse sentido, "quanto mais diversos são os ritmos que nascem pela diferença material entre trabalhos diversos, tanto mais facilmente procede esse desprendimento", bem como "tanto mais resolutamente pode o ritmo converter-se num elemento da vida cotidiana relativamente independente das iniciais circunstâncias desencadeadoras" (LUKÁCS, 1966, p. 274).

Também no sentido de acompanhar as vias da diversificação, desdobramento e generalização do ritmo para outros campos da atuação humana, pode-se destacar a ideia mais geral de acordo com a qual em períodos mais recuados dos processos de humanização é comum que os domínios subjetivos e práticos dos fenômenos e dos processos da realidade natural e social sejam acompanhados ou mesmo "recobertos" por "uma camada mágica" (LUKÁCS, 1966, p. 273). As determinações de base dessa situação geral encontram-se, entre outras, na "experiência do obstáculo insuperável com as forças e os conhecimentos disponíveis", onde "dada a imediatez das emoções e das formas de pensamento", os homens "suspeitam a presença de alguma força desconhecida detrás do obstáculo", de modo que buscam pelas práticas mágicas "submeter essa força à atividade humana ou, pelo menos, influencia-la num sentido favorável” (LUKÁCS, 1966, p. 104).

\section{A análise do trabalho, da}

\section{forma específica da atividade}

humana, que remete aos seus

desdobramentos na

constituição de um mundo

próprio, social, de objetos e

relações, e à expansão desse

mundo, das categorias sociais

objetivas e subjetivas, atesta

que o homem, nos seus

processos autoconstitutivos,

busca e precisa submeter a si

não apenas as forças da

natureza, mas também as

forças e relações que são

socialmente desencadeadas,

postas.

Uma forma primária de ligação entre o sentido humano e cismundano do ritmo como elemento potencializador dos processos e resultados do trabalho e o sentido transcendente do ritmo como elemento constitutivo de representações e práticas mágicas pode ser localizada nas repercussões e na dinâmica evocativa que o mesmo materializa e dispara, nas referidas circunstâncias sociomateriais mais recuadas, nos processos de humanização, repercussões e dinâmica evocativa que são potencializadas, ressalte-se, pelos cantos de trabalho. Sobre essa duplicidade, Lukács considera que "inclusive para os homens de culturas mais elevadas o ritmo exerce uma espécie de "feitiço", ou seja, "por uma parte, produz uma intensificação da nossa autoconsciência, da nossa capacidade de dominar o entorno e nossa própria mesmidade, mas sem que, por outra parte, nos ponhamos esclarecidos da procedência desse poder e dos meios pelos quais atua" (LUKÁCS, 1966, p. 288).

Tanto nas formas reativas no metabolismo homemnatureza, como nas formas de reflexo que vão se constituindo e se desdobrando sobre essas bases primárias, a categoria da evocação, sua gênese e sua peculiaridade, está ligada ao caráter formal do ritmo humanamente desencadeado. Esse caráter formal se mostra, numa de suas dimensões fundamentais, na função ordenadora, regularizadora e homogeneizadora que toda ritmização implica e põe em movimento - seja nos movimentos e cadências do trabalho, seja em campos de atuação mais espiritualizados -, caráter e função que concorrem para a intensificação da potência evocativa e emuladora que o ritmo desencadeia, na efetivação de processos que despertam e fomentam a autoconsciência humana.

Para além das relações e dos traços comuns sinalizados acima, pode-se destacar que a categoria da evocação se situa e desempenha funções distintas, específicas, nas formas reativas ligadas aos processos de trabalho e nas for mas de reflexo desses processos primários. Nesse sentido, um traço distintivo fundamental consiste em que nos processos de trabalho os pôres teleológicos são potencializados pela regularização dos movimentos, sendo que as sensações, os sentimentos e força evocativa que o ritmo engendra são repercussões e desdobramentos que acompanham essa dinâmica primária da relação ativa e consciente do homem com o mundo externo, para o que concorre, inclusive, uma relativa "des-subjetivização" ou "desantropomorfização" do sujeito na reprodução ideal e no lidar com as categorias da realidade. Distintamente, nos processos em que o ritmo, como domínio interno, possessão subjetiva, autoconsciente, dos homens, é aplicado "conscientemente, a evocação se faz meta", "se faz télos" (LUKÁCS, 1966, p. 294), ou seja, deixa o lugar acessório e assume um primeiro plano. 
Essa inflexão assinala o surgimento de novas capacidades, predicados e âmbitos da atuação humana. A evocação que "se faz télos" nos ritmos e cantos de acompanhamento de atividades humanas mais espiritualizadas corresponde, em termos gerais, a processos antropomorfizadores, ou seja, processos de "projeção", externalização e materialização das vivências e "experiências internas do homem sobre a realidade objetiva" (LUKÁCS, 1966, p. 226). Nessas formas de reflexo e conformação de mundo antropomorfizadoras, terrenais e cismundanas, o ritmo, como elemento formal das composições que vão assumindo caráter estético, desempenha, pelo menos, além da já assinalada "função" formal "unificadora, homogeneizadora de conteúdos heterogêneos", a função, igualmente formal, de "eleição do importante, na eliminação do detalhe acessório", além da função de "criar uma atmosfera unitária para a totalidade de uma obra concreta" (LUKÁCS, 1966, p. 291).

De todo modo, é o incremento das capacidades produtivas sociais, a expansão e o adensamento do mundo próprio do homem que fomenta e faculta o estabelecimento da evocação de caráter terrenal como meta e télos, numa dinâmica reflexiva que coloca o "homem no centro" desses processos, como sujeito e como objeto. Lukács considera que "o princípio antropomorfizador", assentado em bases cismundanas, não constitui "nenhuma limitação do horizonte, nenhuma deficiência, nenhuma falsa projeção em um mundo de objetos mágico-fictício, senão o descobrimento de um mundo novo para o homem: o mundo do homem" (LUKÁCS, 1967, p. 294).

Os processos de expansão e "intensificação da nossa autoconsciência, da nossa capacidade de dominar o entorno e nossa própria mesmidade" (LUKÁCS, 1966, p. 288) serão considerados no passo seguinte do presente artigo a partir de referências histórico-concretas, com a análise recaindo sobre os vissungos, cantos de trabalho, luta e resistência dos negros escravizados na mineração, quando serão consideradas as imbricações das determinações ontogenéticas das categorias sociais e das categorias estéticas com formas determinadas da socialidade, onde as conformações da autoconsciência e das antropomorfizações de caráter estético, igualmente, adquirem novas qualidades, âmbitos e matizes.

\section{Vissungos, cantos de trabalho, resistência e luta dos negros escravizados na mineração}

Machado Filho, no livro O negro e o garimpo em Minas Gerais (1985), em pesquisa arqueológica realizada em São João da Chapada e Quartel do Indaiá, município de Diamantina-MG, iniciada no final da década de 1920 e desenvolvida ao longo da década seguinte, situa os vissungos como "cantigas em língua africana ouvidas outrora nos serviços da mineração" (MACHADO FILHO, 1985, p. 13)1. Também em aproximação ao conceito desses "cantos de trabalho" (MACHADO FILHO, 1985, p. 65), vale citar que, "pelo geral, dividem-se os vissungos em boiado, que é o solo, tirado pelo mestre sem acompanhamento nenhum, e o dobrado, que é a resposta dos outros em coro, às vezes com acompanhamento de ruídos feitos com os próprios instrumentos usados na tarefa" (MACHADO FILHO, 1985, p. 65) 2 .

Esses cantos de trabalho são o objeto sobre o qual se volta e concentra, neste passo, o presente artigo. Trata-se, pois, de uma expressão simbólico-cultural claramente marcada e determinada no âmbito da historicidade concreta, vale dizer, uma expressão cultural que se erige sobre bases sociomateriais específicas, singulares, bases que, nos limites das presentes considerações, ficam referidas e tracejadas, em linhas gerais, como aquelas próprias às relações contraditórias, atravessadas pela violência e opressão da dominação material, econômica, classista - e das lutas de classe - nas estruturas produtivas do Brasil-colônia, da "empresa mercantil colonial" (CHASIN, 2000, p. 44) - ou, em outros termos, nas relações de produção e reprodução social que se estabelecem e se desdobram a partir do "assim chamado "antigo sistema colonial"” (FERNANDES, 2009 , p. 23) e, depois, nas estruturas produtivas do "capitalismo dependente" (FERNANDES, 2009, p. 16). Nessas estruturas, para mencionar uma determinação de base, fundamental, principal, específica, o excedente econômico socialmente produzido é expropriado dos produtores, em relações nas quais a força de trabalho é explorada à exaustão, especialmente, a força de trabalho do povo negro, nos grilhões da escravidão, nos quais a produção de riqueza como desprodução da vida é levada aos extremos, muitas vezes, à morte.

Sobre essas bases, os vissungos, os cantos de trabalho dos negros escravizados na mineração, na complexidade e na riqueza da sua constituição musical, rítmica, poética, social, constituem uma forma específica na qual o povo negro escravizado forja seus processos de autoconsciência, de resistência e luta subjetiva, como preparação para as exigências e as lutas práticas da vida, de defesa e construção da existência. Pode-se considerar que os princípios formais, ordenadores, evocadores, do ritmo, assim como a força emuladora dos cantos que acompanham os movimentos e cadências do trabalho, expressam formas e conteúdos emocionais, sentimentos e disposições subjetivas ligados a essas bases sociomateriais concretas, contraditórias, classistas.

Um indicador dessas imbricações pode ser tomado, nos limites do presente estudo, pela consideração e análise das letras dos vissungos. Essa consideração e análise serão feitas, nos parágrafos que seguem, acompanhando dois agrupamentos dos cantos que representam, o primeiro deles, as imbricações entre 
vissungos e representações, por assim dizer, de caráter místico, e o segundo deles, as imbricações entre vissungos e representações subjetivas de resistência, luta e prospecção libertária. Esta delimitação, evidentemente, não constitui mais do que uma aproximação das letras desses cantos que abarcam e tematizam várias situações da sociabilidade e da vida cotidiana.

Assim, vale citar que o vissungo número 50 é registrado por Machado Filho com a seguinte letra: "Ombera, tutimba/ Omber tutimba/ ô calunga, ô tomara, ô tavira" (MACHADO FILHO, 1985, p. 89). O fundamento 3 ou explicação do canto pesquisado pelo autor é o seguinte: "Pedindo chuva. Esta melodia reproduz o canto do sabiá. Serve para pedir chuva, às vezes tão esperada nos serviços de mineração. Existe a crença de que o sabiá quando canta, chama a chuva, prenuncia mudança de tempo" (MACHADO FILHO, 1985, p. 89) ${ }^{4}$.

Também para ilustrar a imbricação entre vissungos e formas subjetivas místicas, pode-se referir o vissungo número 26, cuja letra é a seguinte: "Uanga ô assomá/ qui popiá,/ qui dendengá/ uanga auê/ Uanga ô assomá,/ qui popiá,/ qui dendengá/ uanga auê, ererê" (MACHADO FILHO, 1985, p. 83). O fundamento deste vissungo é apresentado nos seguintes termos:

(O trabalhador se queixa de estar com feitiço, por conseguinte não pode trabalhar). Os cantores enfeitiçavam os rivais, tirando-lhes a voz. Para isso, como ficou dito, entoavam melopeias prostrados no chão, com a boca colada à terra. Ainda hoje apontam-se casos concretos de tais feitiçarias. Alguns feiticeiros tinham poder de chamar nuvens de marimbondos, que iam atormentar os negros do grupo adversário (MACHADO FILHO, 1985, p. 89).

Para consideração e análise daqueles vissungos que expressam representações subjetivas de resistência, luta e prospecção libertária, vale citar o vissungo número 38, onde registra-se a letra: "E! mia pai!/ Ererê! mia mãe/ O Tijuco combaro quilombo/ maiauê!/ ê lê lê, mia pai, ê" (MACHADO FILHO, 1985, p. 86). O fundamento deste vissungo é: "no quilombo, o negro evoca a lembrança de pai e mãe, que estavam no arraial do Tijuco" (MACHADO FILHO, 1985, p. 89). O vissungo número 46 traz a seguinte letra: "Papai auê/ Mamãe, papai, auê/ Iô fero a, siquê/ têquirombô maianê/ a ê, mamãe, ê" (MACHADO FILHO, 1985, p. 8889). Seu fundamento é: "clamando saudades dos pais" (Machado Filho, 1985, p. 89). O vissungo 61 traz a seguinte letra: "Ei ê lambá/ quero me cabá no sumido/ que me cabá no sumido/ lamba de 20 dia/ ei lambá/ quero me cabá no sumido" (MACHADO FILHO, 1985, p. 93). Seu fundamento é: "o negro queixa-se do serviço duro (lambá) e pede a morte" (MACHADO FILHO, 1985, p. 93). Por fim, vale citar o vissungo número 62, cuja letra traz: "Solo: Muriquinho piquinino/ ô parente,/ muriquinho piquinino/ de quissamba no cacunda Purugunta adonde vai/ ô parente/ Purugunta adonde vai/ Pru quilombo do Dumbá/ Coro: Ei, chora-chora mgongo é devera/ chora, mgongo, chora (bis)" (MACHADO FILHO, 1985, p. 93). O fundamento apresentado para esse vissungo é: "O moleque, de trouxa às costas, vai fugindo para o quilombo do Dumbá. Os outros que ficam choram não poder ir também" (MACHADO FILHO, 1985, p. 93).

A lembrança e a saudade dos pais, das origens, da vida na terra mátria, a queixa e a resistência à espoliação extrema, bem como a prospecção, a tensão e a ânsia pela vida no quilombo, são indicadores inequívocos dos conteúdos e das paixões que estão presentes nos vissungos ${ }^{5}$. Em sentido forte, os vissungos correspondem às formas mediante as quais o povo negro, nos grilhões da escravidão, busca "dominar o entorno e a própria mesmidade", em relações onde "dominar o entorno" significa forjar as formas de resistência e luta, subjetivas, mas também práticas, nas relações contraditórias, de dominação classista, da escravidão. Essas formas, em suas especificidades, conforme os argumentos ora apresentados e defendidos, possibilitam a tonificação da subjetividade, a preparação dos sujeitos para as lutas que a vida exige, o fomento da resistência e da prospecção libertadora, do rompimento com as correntes e grilhões que negam a vida, bem como, fortalecem os processos do tomar nas mãos as rédeas da condução da vida, da autodeterminação do povo negro, na direção da construção de uma sociabilidade emancipada das relações de poder e dominação material e simbólico-cultural.

\section{Considerações finais}

A argumentação desenvolvida no primeiro movimento de estudo confirma a possibilidade e a importância do tratamento das categorias sociais e das categorias estéticas a partir da referência mais fundamental, matricial, dos processos de humanização, o que confronta e refuta as concepções apriorísticas das atividades "espirituais" do homem, que nada mais são do que formas específicas mediante as quais os homens forjam e desenvolvem, nos seus processos autoconstitutivos, as respostas às necessidades e imperativos sociomateriais da construção da sua existência. Constata-se a fecundidade da tese que toma as formas abstratas do reflexo da realidade, nascidas e impulsionadas com o trabalho, como uma das vias pelas quais vão se forjando as capacidades estéticas e artísti- 
cas do homem. O que se verifica, no caso da presente delimitação, na análise do ritmo como forma abstrata do reflexo da realidade, como princípio formal e ordenador das atividades humanas, desde aquelas inscritas nas formas reativas próprias do metabolismo homem-natureza, até aquelas que concernem ao reflexo da realidade e aos âmbitos da atividade mais "espiritualizadas" do homem. O princípio ordenador, pelos argumentos desenvolvidos, imbrica-se à potência evocativa do ritmo, bem como ao despertar e ao fomentar da autoconsciência, na projeção de vivências e experiências antropomorfizadoras e antropocêntricas que se materializam, por exemplo, nos cantos de trabalho, nos processos de engendramento das capacidades e categorias estéticas dos homens e, por essas vias, na ampliação das suas capacidades de domínio do entorno e de si.

A argumentação desenvolvida no segundo movimento de estudo demonstra que não há aporia ou relação de excludência entre enunciados e categorias de caráter mais geral, formados sobre as bases da história, e enunciados e categorias sociais mais específicos, radicados em formações sociais determinadas. No caso, a análise mostra que uma formação social determinada traz em si uma riqueza e multiplicidade de determinações que não só confirmam e constituem aquelas mais gerais, por exemplo, ontogenéticas, como abrem para a mais rica compreensão da generidade humana em suas expressões mais concretas. Os vissungos, nesse sentido, não obstante as relações de violência que estão nas suas bases de formação, constituem uma forma de expressão simbólico-cultural do povo negro, nas suas lutas e resistências históricas, uma forma que tanto integra a memória genérica do humano, em seus caminhos e descaminhos contraditórios, como também uma forma que em sentido ontológico incide - ou ao menos pode incidir - sobre o presente e sobre o futuro. Assim, as categorias inicialmente tratadas em termos gerais, tateadas em sua ontogênese e em suas peculiaridades, assumem neste movimento de concreção uma fisionomia muito mais rica e saturada de determinações e de socialidade.

\section{Referências}

CHASIN, J. A miséria brasileira: 1964-1994: Do golpe militar à crise social. Santo André: Ad Hominem, 2000.

FERNANDES, F. Capitalismo dependente e classes sociais na América Latina. 4. ed. São Paulo: Global, 2009.

LUKÁCS, G. Estética I: la peculiaridad de lo estetico. Barcelona; México: Grijalbo, 1966.

LUKÁCS, G. 2. Problemas de la mínesis. In: LUKÁCS, G. Estética I: la peculiaridad de lo estetico. Barcelona; México: Grijalbo, 1967. p. 7-544. Vol. 2 .

LUKÁCS, G. 3. Categorías psicológicas y filosóficas básicas de lo estético. In: LUKÁCS, G. Estética I: la peculiaridad de lo estetico. Barcelona; México: Grijalbo, 1967. p. 7-343. Vol. 3.

LUKÁCS, G. 4: Cuestiones liminares de lo estetico. In: LUKÁCS, G. Estética I: la peculiaridad de lo estetico. Barcelona; México: Grijalbo, 1967. p. 7-296. Vol. 4.

LUKÁCS, G. Para uma ontologia do ser social II. Tradução de Nélio Schneider, Ivo Tonet e Ronaldo Vielmi Fortes. São Paulo: Boitempo, 2013.

MACHADO FILHO, A. M. O negro e o garimpo em Minas Gerais. Belo Horizonte: Itatiaia; São Paulo: Edusp, 1985.

MAGALHÃES, D. Emo quá, um vissungo. In: SAMPAIO, N. F. (Org.) Vissungos: cantos afrodescendentes em Minas Gerais. $2^{\mathrm{a}}$ ed. rev. aum. Belo Horizonte: Edições Viva Voz, 2009.

MARX, K. Manuscritos Econômico-Filosóficos. São Paulo: Boitempo, 2010.

MARX, K; ENGELS, F. A Ideologia Alemã. São Paulo: Boitempo, 2007.

QUEIROZ, S. Vozes da África em terras diamantinas. In: Suplemento Literário de Minas Gerais. Secretaria de Estado de Cultura de Minas Gerais. Cantos afro-descendentes - vissungos, Belo Horizonte, edição especial, outubro de 2008.

QUEIROZ, S. Cantos afro-descendentes de morte e vida. In: SAMPAIO, N. F. (Org.) Vissungos: cantos afrodescendentes em Minas Gerais. $2^{\mathrm{a}}$ ed. rev. aum. Belo Horizonte: Edições Viva Voz, 2009.

SAMPAIO, N. F. (Org.) Vissungos: cantos afrodescendentes em Minas Gerais. $2^{\mathrm{a}}$ ed. rev. aum. Belo Horizonte: Edições Viva Voz, 2009. VISSUNGO: fragmentos da tradição oral. Direção: Cássio Gusson, Contra-filmes, 2009. 13 min. Disponível em: https://curtadoc.tv/ curta/cultura-popular/vissungo-fragmentos-da-tradicao-oral/

\section{Notas}

1 “Os vissungos [...] foram identificados pelo pesquisador Aires da Mata Machado Filho em 1928 nos povoados de São João da Chapadae Quartel do Indaiá, no município de Diamantina (MG). Entre 1939 e 1940, Aires publicou em capítulos, na Revista do Arquivo Municipal, de São Paulo, o resultado de sua pesquisa sobre esses cantos de tradição banto: 65 cantigas, com 'letra, música e tradução, ou antes 'fundamento", além de dois glossários da 'língua banguela' (que ele também nomeia, equivocadamente, 'dialeto crioulo') - um extraído dos cantos e o outro, do linguajar local; e 8 capítulos de estudo sobre a cultura afro-brasileira no contexto do trabalho da mineração de diamantes. A primeira edição em livro saiu pela José Olympio, em 1943, e a segunda, em 1964, pela Civilização Brasileira. Em 1985, a editora Itatiaia publicou uma co-edição com a EDUSP, que ainda 
se encontra no mercado" (QUEIROZ, 2008, p. 1). Para uma aproximação a esse material, ver também Queiroz, 2009.

2 É importante destacar a complexidade dos vissungos, relacionada, por exemplo, à sua abrangência, que compreende um universo simbólico e cultural que remete, nas suas formas matriciais, à vida em terras africanas, mas também aos processos históricos que vão do período da escravidão em terras brasileiras às relações sociais que alcançam os séculos XIX e XX. Os registros de Machado Filho, datados dos anos de 1920 e 1930 reúnem um material que sintetiza esse largo e polimórfico âmbito sócio-histórico. Sampaio (2009), no livro "Vissungos, cantos afrodescendentes em Minas Gerais", considera que "os vissungos são cantos afro-brasileiros cantados em Minas Gerais em diversas situações da vida cotidiana. Durante o trabalho nas minas e no trabalho dos terreiros, nas brincadeiras ou no cortejo dos enterros, os negros escravizados preservavam sua cultura à revelia dos senhores através da música. E também através da língua, uma vez que esses cantos ainda hoje mantêm muitas palavras originárias de línguas africanas" (SAMPAIO, 2009, p. 7). Para Magalhães (2009), os vissungos, no âmbito musical afro-mineiro, correspondem a um "[...] gênero musical de marcada origem africana de tradição banto, normalmente vinculado a um número variado de funçães, identificadas pelo pesquisador Aires da Mata Machado Filho no livro O negro e o garimpo em Minas Gerais: padre-nossos, cantos da manhã, cantos do meio-dia, cantigas de multa, cantigas de rede, cantigas de caminho, cantigas de pedir licença para cantar" (MAGALHÃES, 2009, p. 34-35).

3 "Tradução ou ideia geral do vissungo fornecida pelos entrevistados, mas não uma tradução literal, palavra por palavra" (SAMPAIO, 2009, p. 9).

4 Para uma aproximação das determinações ontogenéticas mais gerais abordadas no primeiro movimento do presente artigo aos estudos mais concretos, de caráter científico, concentrados sobre o caráter e o papel "mágicos" que o ritmo desempenha em culturas específicas, considere-se a seguinte citação que Machado Filho (1985) faz de Lèvy-Bruhl: “'O tambor tem... independentemente de seu efeito psicológico, bem conhecido dos indígenas, uma ação mística própria. Ele exerce uma influência sobre as disposições dos seres invisíveis como sobre as dos humanos. Éassim o acompanhamento obrigatório de todas as cerimônias, em que o grupo se acha em contato com as forças sobrenaturais invisíveis, esforçando-se por incliná-las a seu favor. Do ponto de vista místico, é elemento indispensável do material mágico-propiciatório' (Lévy-Bruhl, citando a Rev. J. H. Weeks. Apud Artur Ramos, O Negro Brasileiro, p. 163)" (MACHADO FILHO, 1985, p. 70-71).

5 Nas suas pesquisas, Lukács faz uma observação que vale reproduzir aqui. Ele se refere que já o filósofo grego Aristóteles “viu nos ritmos e nas melodias refigurações das diversas paixões humanas, da cólera e da suavidade, do valor e da medida, assim como de seus contrários. E por isso em sua opinião estão muito próximos às propriedades e aos sentimentos éticos" (Lukács, 1963, p. 287). Lukács indica e desenvolve em sua obra A peculiaridade do estético essas intersecções entre estética e ética, o que também contribui para a compreensão da função social da arte.

\section{Marlon Garcia da Silva}

longarcia@gmail.com

Doutor em Serviço Social pela Universidade Federal de Santa Catarina (UFSC)

Professor Adjunto do Curso de Serviço Social da Universidade Federal de Ouro Preto (UFOP)

\section{Universidade Federal de Ouro Preto}

Rua do Catete, n. 166, Centro.

Mariana - MG - Brasil

CEP: $35.420-000$

\section{Agradecimentos}

Não se aplica.

\section{Agência financiadora}

Não se aplica.

Contribuições das autoras

Não se aplica.
Aprovação por Comitê de Ética e consentimento para participação

Não se aplica.

Consentimento para publicação

Consentimento do autor.

Conflito de interesses

Não há conflito de interesses. 